\title{
EDITORIAL
}

\section{LOST IN TRANSLATION}

\author{
How can we ensure that the revolutionary advances in biomedical science of recent years are \\ applied to solving the problems posed by the world's great neglected diseases?
}

The revolution in biomedical science over the past 30 years has led to enormous health benefits for mankind. Most of these rewards, however, have been reaped by those in the richer countries of the world. People in developing countries - who account for $\sim 80 \%$ of the world's population but only $20 \%$ of medicine sales - have been largely left behind. Diseases including malaria, tuberculosis and leishmaniasis extract enormous tolls on the quality of life, life expectancy, economic development and social cohesion in the world's poorest countries. Yet this dire situation is not the result of a lack of basic and applied scientific research on these diseases. The problem lies in converting scientific advances into marketable medical interventions for the developing world, something which has little financial incentive for the multibillion-pound pharmaceutical industry.

The well-known ' $90 / 10$ rule' $-90 \%$ of the pharmaceutical industry's global investment in therapeutics treats only $10 \%$ of the world's population - highlights the lack of industry research focus for treating diseases that are predominant in developing countries. Undoubtedly, high-quality innovative research efforts that focus on diseases which afflict poor and marginalized populations are being conducted, and in recent years there has also been a considerable increase in financial investment in combating these diseases. The fact remains, however, that applying biomedical research to the problems posed by the world's neglected diseases presents unique and challenging difficulties over and above the traditional R\&D challenges.

What should be done to facilitate the translation of biomedical advances into health products for neglected diseases? The pharmaceutical industry requires a return on capital as an incentive to discover and develop new drugs. One way to achieve this is to create a differential pricing structure, in which higher costs of drugs in developed countries 'subsidize' the necessary lower costs in developing countries. How this is carried out in practice is a matter of debate at present, with opinion in developed countries suggesting discontent about being 'overcharged' for medications. Achieving an equitable balance between investment incentives for the pharmaceutical industry, affordability in developed countries and access to medicines in developing countries will be crucial.

With the costs associated with the discovery and development of a new drug reaching the billion-dollar mark on average and taking around 15 years, plundering the medicines of the past might identify hidden gems that could bypass this high cost and time investment. A case in point is ivermectin. First introduced to the market in 1981 as a veterinary antiparasitic drug, it has gone on to become the basis of one of the most successful public-health programmes of the past century. The development process also incorporated the world's first and largest drugdonation programme and involved a unique association between governments, non-governmental organizations and industry. The drug is now being used, free of charge, in two global disease-elimination programmes (onchocerciasis and lymphatic filariasis) that are benefiting millions of the world's poorest people. Attention should also be given to the abundance of scientific talent concentrated in the laboratories of the pharmaceutical industry who are successfully tackling the $\mathrm{R} \& \mathrm{D}$ issues that are crucial for progress. In particular, the industry's extensive chemistry expertise could be harnessed though partnership schemes that can allow chemistry experts and their currently unwanted products to be used for the benefit of all. How industry could provide access to this talent has been the topic of frequent discussion without any measurable outcomes. However, recent progress, such as the development of a synthetic form of artemisinin, clearly indicates that industry-academia collaborations are feasible and have considerable potential.

Ultimately, applying the benefits of innovative R\&D in treating infectious diseases requires the appropriate infrastructure on the ground where the problems exist. The long-term sustainability and availability of effective therapies in the world's poorest nations will critically depend on stimulating local R\&D, local manufacturing and the establishment of local health systems. Of all the different proposals and initiatives requiring attention, building this indigenous capacity should be the primary focus. 